\title{
Clay Migration in Proppant during Production in Argillaceous Unconsolidated Reservoir
}

\author{
Weidong Zhanga*, Xuhui Guan, Maoyong Fu and Shouqiang Zhao \\ College of Petroleum Engineering, China University of Petroleum, China \\ *Corresponding author: Weidong Zhanga, College of Petroleum Engineering, China University of Petroleum, Qingdao 266580, China

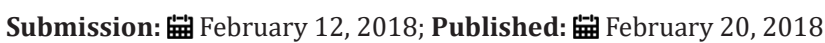

\begin{abstract}
Fine migration inevitably occurs during the process of fracturing production in argillaceous unconsolidated reservoirs. Using the API conductivity cell simulate the process of the production of the reservoir. The damage to conductivity caused by fines migration in the pack and the factors affecting such migration are analyzed. The result indicates that clay are likely to aggregate and be retained in the prop pant pack because of the adsorption and deposition, thereby resulting in pore throat plugging, which causes serious damage to fracture conductivity. The mobility and retention of clay in the prop pant pack are affected by flow rate, fracture closure stress and fines property. This research is important for the further research.
\end{abstract}

Keywords: Unconsolidated sand; Fine migration; Fracture conductivity; Argillaceous unconsolidated reservoir

\section{Introduction}

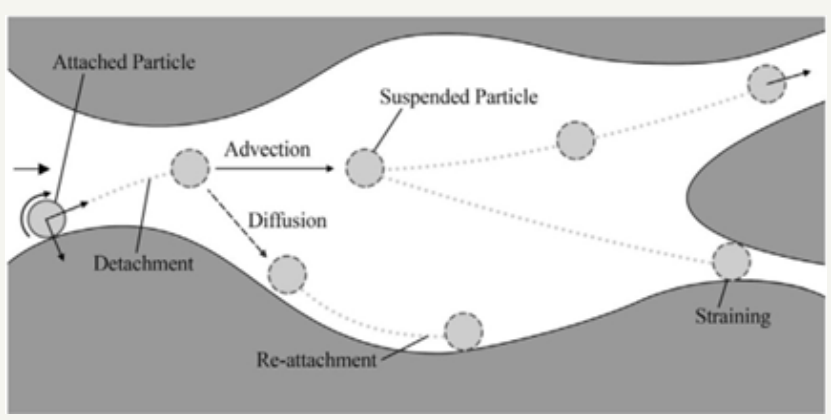

Figure 1: Another view of the newborn with Adams-Oliver syndrome associated with the related disorders.

Fines migration and consequent permeability damage is one of the widest spread physical mechanisms of formation damage in gas and oil fields [1,2]. Lifting of natural reservoir fines at high injection/ production rates with resulting migration and straining usually yields a significant increase in the flow trajectory tortuosity and resulting drastic permeability decline $[2,3]$. Numerous measures focused on fixing the reservoir fines (against fines mobilization) [4-6]. Figure 1 shows the sequential processes of fines detachment from the pore surface, migration and straining in a thin pore throat. Fines-sensitive technologies of oil and gas recovery are primarily focused on enhancing or inhibiting the particle detachment process [7]. However few are focused on the mechanism of the fine migration in the field, fracture and prop pant. So understanding the mechanics of particle migration and the decline degree of permeability in the prop pant is important. The structure of the text is as follows. Section 2 presents the methodology of the laboratory study, including preparation of materials. Section 3present the mechanism of the clay retention. Section 4 describes and analyses the obtained results. Section 5 concludes the paper.

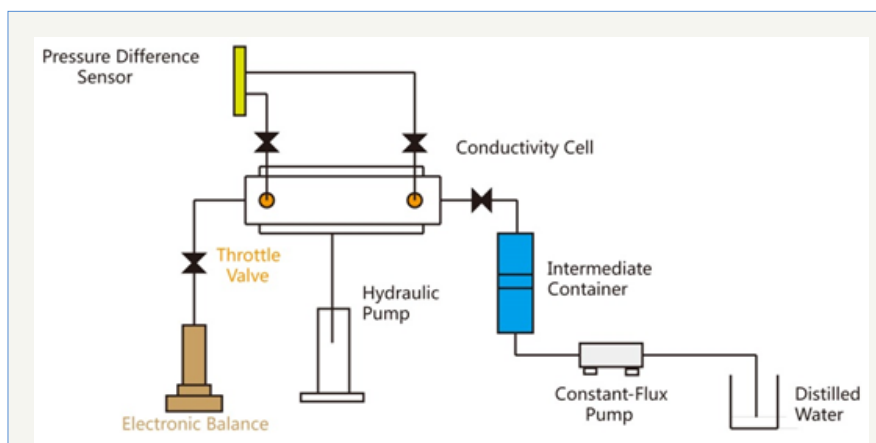

Figure 2: Schematic of fines migration model and conductivity test apparatus.

The experimental apparatus used in this paper are mainly based on a modified API standard fracture conductivity instrument $[8,9]$ that consists of an Automated hydraulic intensifier system, a fluid injection system, and a hastelloy conductivity cell (Figure 2). This instrument can simulate real reservoir conditions. However, the provided flow rate is limited, and a constant-flux pump of maximum flow rate up to $10 \mathrm{~mL} / \mathrm{min}$ is configured. The simulation process of fines invasion into the prop pant pack is presented as follows:

(1) The conductivity cell was paved with high-strength and large-sized ceramsite $(380-830 \mu \mathrm{m})$ from the inlet to outlet. Intermediate container provides mixed suspension which can provide different fines concentrations to represent the formation 
supply capability. Fines consist of $60 \%$ quartz sand, 24\% illite, $6 \%$ montmorillonite, $10 \%$ Plagioclase. The clay size was measured using intelligent laser particle analyzer, as shown in Figure 3.

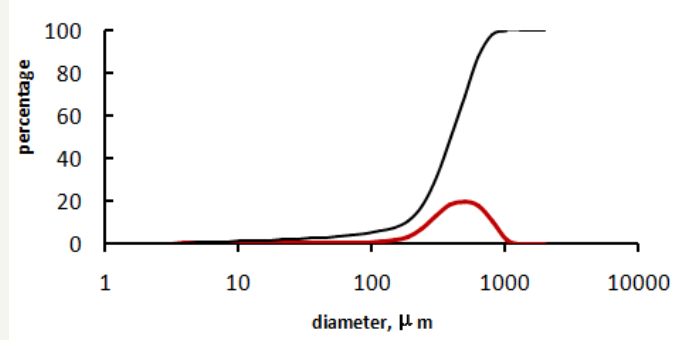

Figure 3: Diameter distribution of clay fines.

(2) The desired closure pressure was applied to the steel plate using the hydraulic pump. The constant-flux pumps then drew to drive suspension to the prop pant pack in the conductivity cell. The production process of the reservoir can be simulated using Steps $1-2$.

\section{Fines Retention Mechanisms}

Filtration and straining are two distinct mechanisms that cause fines retention in porous media [10]. Straining is a geometric mechanism. Fines are retained by straining when they arrive in a pore space that is too small to enable passage. However, the results found in this paper suggest that anomalously small fines, which are smaller than the smallest pore throats in the porous media, can be strained as well. This finding is consistent with experimental results reported by previous studies $[8,11,12]$. The conventional straining model cannot explain this uncharacteristic behavior [11]. Filtration is a physicochemical mechanism controlled by electrostatic, chemical, and van der Waals forces that result in the attachment/ detachment of particles to the filter media. In addition to surface deposition and pore throat binding, the surface properties of clay were found to be greater influencing factors in causing coal fines accumulation in the prop pant pack. The surface characteristics of coal fines include surface area, pore volume and size distribution, wettability, and electrical property [13]. The surface of fines has very strong adsorption because of its greater surface area or pore volume, surface roughness, and surface energy, which cause coal fines to aggregate [14-18].

\section{Results and Discussion}

Experiment results show that clay invading into the prop pant pack would plug the pore throat of the prop pant pack and would cause a sharp decline in fracture conductivity [19-21]. There is a linear relationship between closure pressure and conductivity. This invasion could decrease the conductivity by $50 \%$ when the concentration of coal fines is $3 \%$ and the closure pressure is $16 \mathrm{MPa}$. Moreover, the damage would rapidly worsen with increasing fines concentration. When fines concentration reaches $5 \%$, the pore throat of the prop pant pack would be completely blocked, and no conductivity would be available under 16MPa (Figure $4 \& 5$ ). Different damage degree can be seen from Figure 6. This finding indicates that when the qualities of fines retention in the prop pant pack increase, propped fractures conductivity would decrease. In order to mitigate conductivity damage, few fines should be allowed to enter prop pant pack. The effects of flow rate and clay concentration on conductivity damage are shown in Figure 5 \& 6 , respectively. The discharge of fluid at different rates and the measurement of the corresponding conductivity are shown in Figure 5. Under a 16MPa closure pressure, flow rate changed from 3 to $10 \mathrm{~mL} / \mathrm{min}$ much more clay are retained in the pore throat at higher fluid rate because of their strong adsorption property, thereby causing an inevitable decrease in conductivity, as shown in Figure 5. The prop pant pack with higher clay concentration has more retention (Figure 6). In addition, the formation of effective flow path scan is seen during the experiments, which provide and retain effective fracture conductivity as shown in the Figure7.

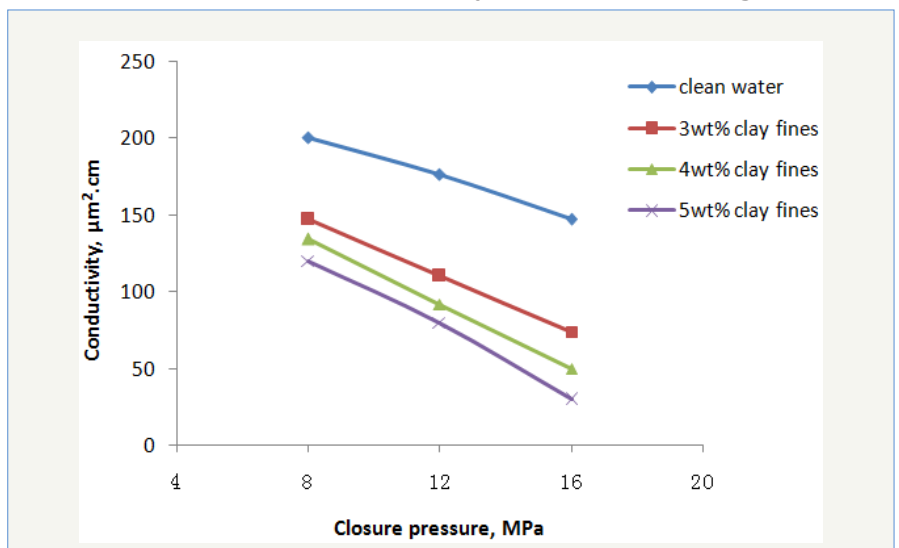

Figure 4: Effect of fracture close pressure on conductivity.

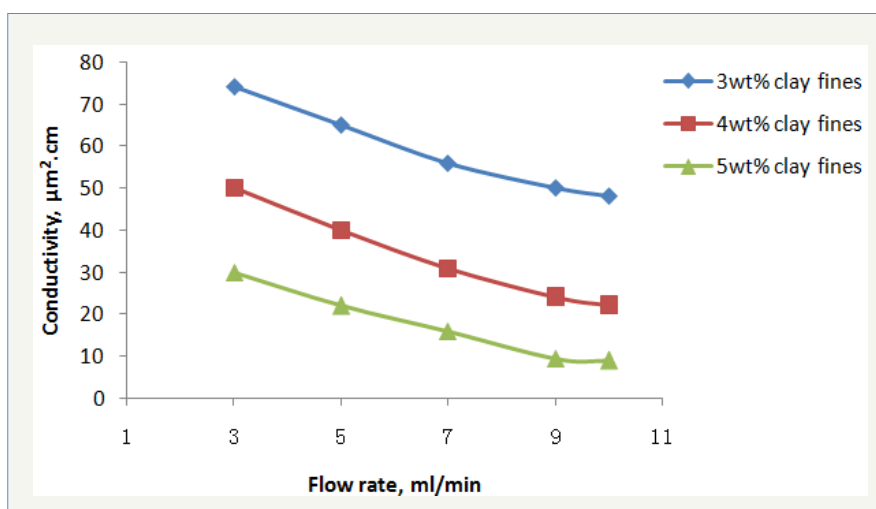

Figure 5: Effect of coal fines concentration on conductivity.
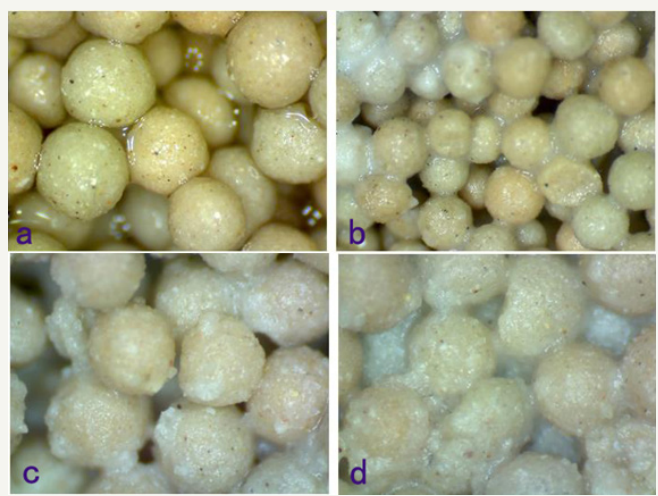

Figure 6: High-magnification view of proppant pack invaded by fines. a: clean water; b: $3 w t \%$ clay; c: $4 w t \%$ clay; d: $5 w t \%$ clay. 


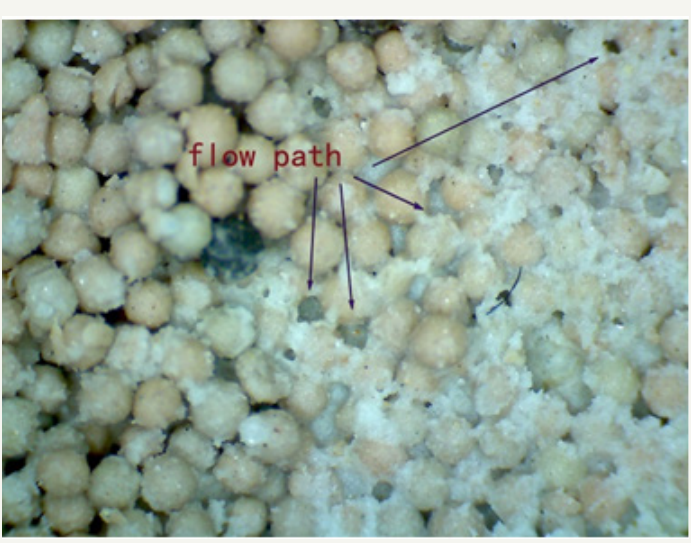

Figure 7: The formation of flow paths.

\section{Conclusion}

1. An effective experimental method that could simulate the process of fine migration in the prop pant pack was proposed.

2. Fines retention seriously damages fracture conductivity. The damage significantly worsens with increasing clay concentration and fracture closure pressure. Only 3\% clay can decrease conductivity by $50 \%$, whereas $5 \%$ fines can cause the fracture to lose conductivity completely.

3. Flow paths form in the flow of the plugging, which is the main reason that keeps the permeability of the reservoir. Flow path can keep a steady condition while a constant flow and concentration is steady during a long period.

4. Formation clay should not be allowed to enter the prop pant pack. Injecting non-fluids into reservoir should be suggested to take into consideration.

\section{Acknowledgment}

This research is supported by the National Natural Science Foundation of China (Project no.51374229).

\section{References}

1. Khilar KC, Fogler HS (1998) Migration of fines in porous media. Kluwer Academic Publishers, USA.

2. Byrne M, Waggoner S (2009) Fines migration in a high temperature gas reservoir-laboratory simulation and implications for completion design. Society of Petroleum Engineers.

3. Zeinijahromi A, Farajzadeh R, Bruining J, Bedrikovetsky P (2016) Effect of fines migration on oil-water relative permeability during two-phase flow in porous media. Fuel 176: 222-236.

4. Habibi A, Pourafshari P, Ahmadi M, Ayatollahi S (2013) Reduction of fine migration by nanofluids injection, an experimental study. Notre Dame L rev 18(2): 374-384.
5. Assef Y, Arab D, Pourafshary P (2014) Application of nanofluid to control fines migration to improve the performance of low salinity water flooding andalkaline flooding. J Petrol Sci Eng 124: 331-340.

6. Yuan B, Moghanloo RG, Pattamasingh P (2015) Applying method of characteristics to study utilization of nanoparticles to reduce fines migration in deepwater reservoirs. SPE European Formation Damage Conference and Exhibition, SPE 174192.

7. Yuan B, Moghanloo R, Zheng D (2016) Analytical evaluation of Nanoparticle application to mitigate fines migration in porous media. SPE Journal.

8. Marlow HJ, Duston KL, Wiesner MR, Tomson MB, Wilson JT, et al. (1991) Microbial transport through porous media: the effects of hydraulic conductivity and injection velocity. Journal of Hazardous Materials 28(1): 65-74.

9. Nguyen PD, Weaver JD, Rickman RD, Dusterhoft RG, Parker MA (2007) Controlling formation fines at their sources to maintain well productivity. Spe Production \& Operations 22(2): 202-215.

10. Rodriguez E, Bryant S (2007) Straining of fine particles in gaps in porous media. Society of Petroleum Engineers.

11. Gruesbeck C, Collins RE (1982) Entrainment and deposition of fine particles in porous media. Soc Pet Eng AIME 6(6): 847-856.

12. Bryant SL, King PR, Mellor DW (1993) Network model evaluation of permeability and spatial correlation in a real random sphere packing. Transport in Porous Media 11(1): 53-70.

13. Rong RX, Hitchins J (1995) Preliminary study of correlations between fine coal characteristics and properties and their dewatering behaviour. Minerals Engineering 8(3): 293-309.

14. Baghdikian SY, Sharma MM, Handy LL (1989) Flow of clay suspensions through porous media. Society of Petroleum Engineers 4(2): SPE16257-PA.

15. Blauch M, Weaver J, Parker M, Todd B, Glovor M (1999) New insights into proppant-pack damage due to infiltration of formation fines. SPE Annual Technical Conference and Exhibition, Houston, Texas, SPE 56833.

16. El-Monier IA, Nasr-El-D HA (2011) Mitigation of fines migration using a new clay stabilizer: a mechanistic study. SPE European Formation Damage Conference, Noordwijk, The Netherlands, SPE 144180.

17. Huang T, Crews JB, Willingham JR (2008) Nanoparticles for formation fines fixation and improving performance of surfactant structure fluids. International Petroleum Technology Conference, Malaysia, IPTC 12414.

18. Haug MD, Wong LC (1992) Impact of molding water content on hydraulic conductivity of compacted sand-bentonite. Can Geotech J 29(2): 253262.

19. Ruckenstein E, Prieve DC (1976) Adsorption and desorption of particles and their chromatographic separation. Am Inst Chem Eng J 22 (2): 276283.

20. Schembre KM, Kovscek AR (2005) Mechanism of formation damage at elevated temperature. J Energy Resour Technol 127(3): 171-180.

21. Shani C, Weisbrod N, Yakirevich A (1998) Colloid transport through saturatedsand columns: influence of physical and chemical surface properties on deposition. Colloids Surf A Physicochem Eng Asp 316(13): $142-150$. 
Creative Commons Attribution 4.0

International License

For possible submissions Click Here
Your subsequent submission with Crimson Publishers will attain the below benefits

- High-level peer review and editorial services

- Freely accessible online immediately upon publication

- Authors retain the copyright to their work

- Licensing it under a Creative Commons license

- Visibility through different online platforms

- Global attainment for your research

- Article availability in different formats (Pdf, E-pub, Full Text)

- Endless customer service

- Reasonable Membership services

- Reprints availability upon request

- One step article tracking system 